\title{
History and Latest Advances in Flow Estimation Technology: From 1-D in 2-D to 3-D in
} 4-D

\author{
Jensen, Jørgen Arendt; Nikolov, Svetoslav Ivanov; Hansen, Kristoffer Lindskov; Stuart, Matthias Bo; \\ Hoyos, Carlos A. Villagomez ; Schou, Mikkel; Ommen, Martin Lind; Øygard, Sigrid Husebø; Jørgensen, \\ Lasse Thurmann; Traberg, Marie Sand
}

Total number of authors:

16

Published in:

Proceedings of 2019 IEEE International Ultrasonics Symposium

Link to article, DOI:

10.1109/ultsym.2019.8926210

Publication date:

2019

Document Version

Peer reviewed version

Link back to DTU Orbit

Citation (APA):

Jensen, J. A., Nikolov, S. I., Hansen, K. L., Stuart, M. B., Hoyos, C. A. V., Schou, M., Ommen, M. L., Øygard, S. H., Jørgensen, L. T., Traberg, M. S., Nguyen, T-Q., Thomsen, E. V., Larsen, N. B., Beers, C., Tomov, B. G., \& Bachmann Nielsen, M. (2019). History and Latest Advances in Flow Estimation Technology: From 1-D in 2-D to 3-D in 4-D. In Proceedings of 2019 IEEE International Ultrasonics Symposium (pp. 1041-1050). IEEE. https://doi.org/10.1109/ultsym.2019.8926210

\section{General rights}

Copyright and moral rights for the publications made accessible in the public portal are retained by the authors and/or other copyright owners and it is a condition of accessing publications that users recognise and abide by the legal requirements associated with these rights.

- Users may download and print one copy of any publication from the public portal for the purpose of private study or research.

- You may not further distribute the material or use it for any profit-making activity or commercial gain

- You may freely distribute the URL identifying the publication in the public portal 


\title{
History and Latest Advances in Flow Estimation Technology: From 1-D in 2-D to $3-\mathrm{D}$ in $4-\mathrm{D}$
}

\author{
Jørgen Arendt Jensen ${ }^{1}$, Svetoslav Ivanov Nikolov ${ }^{2}$, Kristoffer Lindskov Hansen ${ }^{4}$, Matthias Bo Stuart ${ }^{1}$, \\ Carlos A. Villagomez Hoyos ${ }^{2}$, Mikkel Schou ${ }^{1}$, Martin Lind Ommen ${ }^{1}$, Sigrid Husebø Øygard ${ }^{1}$, \\ Lasse Thumann Jørgensen ${ }^{1}$, Marie Sand Traberg ${ }^{1}$, Tin-Quoc Nguyen ${ }^{4}$, Erik Vilain Thomsen ${ }^{1}$, \\ Niels Bent Larsen ${ }^{1}$, Christopher Beers ${ }^{3}$, Borislav Gueorguiev Tomov ${ }^{1}$, and Michael Bachmann Nielsen ${ }^{4}$ \\ ${ }^{1}$ Department of Health Technology, Technical University of Denmark, Lyngby, Denmark \\ ${ }^{2}$ BK Medical, Herlev, Denmark, ${ }^{3}$ BK Medical, State College, PA 16803, USA, \\ ${ }^{4}$ Department of Diagnostic Radiology, Rigshospitalet, Denmark
}

\begin{abstract}
Ultrasound imaging of flow has seen a tremendous development over the last sixty years from 1-D spectral displays to color flow mapping and the latest Vector Flow Imaging (VFI). The paper gives an overview of the development from current commercial vector flow systems to the latest advances in fast 4-D volumetric visualizations. It includes a description of the radical break with the current sequential data acquisition by the introduction of synthetic aperture imaging, where the whole region of interest is insonified using either spherical or plane waves also known as ultrafast imaging. This makes it possible to track flow continuously in all directions at frame rates of thousands of images per second. The latest research translates this to full volumetric imaging by employing matrix arrays and row-column arrays for full 3-D vector velocity estimation at all spatial points visualized at very high volume rates (4-D).
\end{abstract}

\section{INTRODUCTION}

The measurement of blood flow has undergone a tremendous development since the first system devised by Satomura in Japan in 1957 and 1959 [1, 2] more than sixty years ago. The continuous wave system could detect heart wall movements and flow patterns in peripheral arteries. Pulsed systems developed by Baker [3] and Wells [4] could display the spectral content of the flow signals at one depth in the vessel. These early 1-D systems forms the basis for the spectral Doppler systems of today, which are used for investigating and quantifying flow everywhere in the human circulation. Even the continuous wave systems are still in use in cardiology, where the velocities can be too high to measure for a pulsed system. Both yield quantitative estimates but can only measure at a single spatial location.

This limit was lifted by the Color Flow Mapping (CFM) system developed by Kasai et al [5, 6], where an autocorrelation estimator can estimate the velocity from only 8 to 16 emissions, thereby making it possible to acquire and display axial velocity images. This introduced the second most important innovation in velocity estimation, which is implemented in all commercial scanners for flow imaging of the vessels and the heart. The estimator has been investigated and improved in numerous papers using e.g. both RF averaging $[7,8]$ and cross-correlation [9, 10].
Although these systems are widely used in the clinic, and a whole range of diagnostic measures are routinely used, they also have a number of drawbacks and technical problems. Most importantly, only the axial velocity component is estimated. This is often compensated for by finding the beamto-flow angle using the B-mode image, but it is inherently unreliable as the angle can vary over the cardiac cycle, and the flow is not necessarily parallel to the vessel wall. Often the beam-to-flow angle can be difficult to keep below $60^{\circ}$, and even a modest error of $5^{\circ}$ can here lead to $20-30 \%$ errors in the estimated velocities. In many cases the axial velocity is actually the smallest component for e.g. peripheral vessels, and the lateral component is more important. The problem is addressed by the 2-D Vector Flow Imaging (VFI) systems presented in Section II, which also describes how more accurate measures of flow and turbulence can be attained in Section II-B.

A second problem is that CFM systems are limited in their frame rate by the sequential data acquisition due to the speed of sound $[11,12]$. Eight to sixteen emissions must be acquired in multiple directions to yield an image, and the precision of the velocity estimates is limited by the number of emissions in the same direction. It is, thus, not possible to have both a large imaging region (large depth), fast frame rates, and precise estimates at the same time. Further, it is often difficult to detect flow in both the systolic and diastolic phase. The limits number of lines making low velocity estimation difficult, if aliasing should be avoided at the same time. These problems are addressed in Section III with the introduction of Synthetic Aperture (SA) systems, which radically breaks the trade-off between frame rate and precision [12]. It opens a whole range of new possibilities for flow imaging, where both slow and fast velocities can be estimated from the same data with a very high precision.

The third problem is that current systems only show flow in a 2-D image. Recently, 3-D volumetric imaging has been introduced, and these systems can show CFM images in a volume. Even though parallel beamforming is employed, it is still difficult to attain decent frame rates for real-time 
cardiac imaging, and often the scanners have to resort to ECG gated sequences to stitch the volume together from multiple acquisitions. A further problem is the use of matrix array probes. Attaining a high resolution and contrast in ultrasound images require 64 to 128 transducer elements along the imaging plane, and for 3-D volumetric imaging matrix probes have to be used. These should ideally have at least 4,000 to 16,000 elements making them prohibitively expensive to develop and costly to use. Current state-of-the-art probes have more than 9,000 elements, which is still too low to attain a state-of-the-art image quality. Further, the velocity estimation is still only in the axial direction and not in full 3-D. These problems are addressed in Section IV, which shows how the latest research in Row-Column (RC) matrix probes potentially can be a solution to the problems of fast 4-D imaging with display of the full 3-D velocity vector in all points in the volume in real time.

\section{2-D Vector Flow IMAGING}

It was early realized that only estimating the axial velocity component was not sufficient to give a complete picture of the complex human blood flow. Fox [13] suggested the first system with two crossing beams to enable estimation of the lateral velocity component from triangulation. This has later been investigated and optimized by a number of authors [14, 15]. A second approach developed by Trahey et al [16] used speckle tracking, where a small search region was correlated to a larger image region. The velocity could then be found for both components.

\section{A. Transverse oscillation}

The first approach to make it into commercial scanners was the Transverse Oscillation (TO) method developed by Jensen, Munk, and Anderson [17, 18]. Axial velocity estimators rely on the sinusoidal signal emitted, and the velocity is estimated by correlating multiple emissions in the same direction. The motion between emissions is then found through either an autocorrelation using the phase shift or a cross-correlation for the time shift [19]. The idea in TO is to introduce an oscillation transverse to the ultrasound beam and then find the lateral displacement. A Fourier relationship exists between the transducer's aperture sensitivity and the lateral far-field sensitivity $[17,20,21]$. Introducing two peaks in the receive apodization therefore generates a lateral oscillation, where the frequency is determined by the separation of the two peaks. A dedicated estimator was developed for separately estimating the axial and lateral velocity components [22]. The method was implemented on BK Medical scanners (Herlev, Denmark) and FDA approved in 2012 [23]. It made it possible for the first time to visualize the complex flow in the body in real-time, and vortices in e.g. the bulbous of the carotid artery could be seen as shown in Fig. 1. The approach has been implemented on linear [17, 22], convex [24], and phased array probes [25] and can also be used for finding the spectrum of the transverse velocity [26].
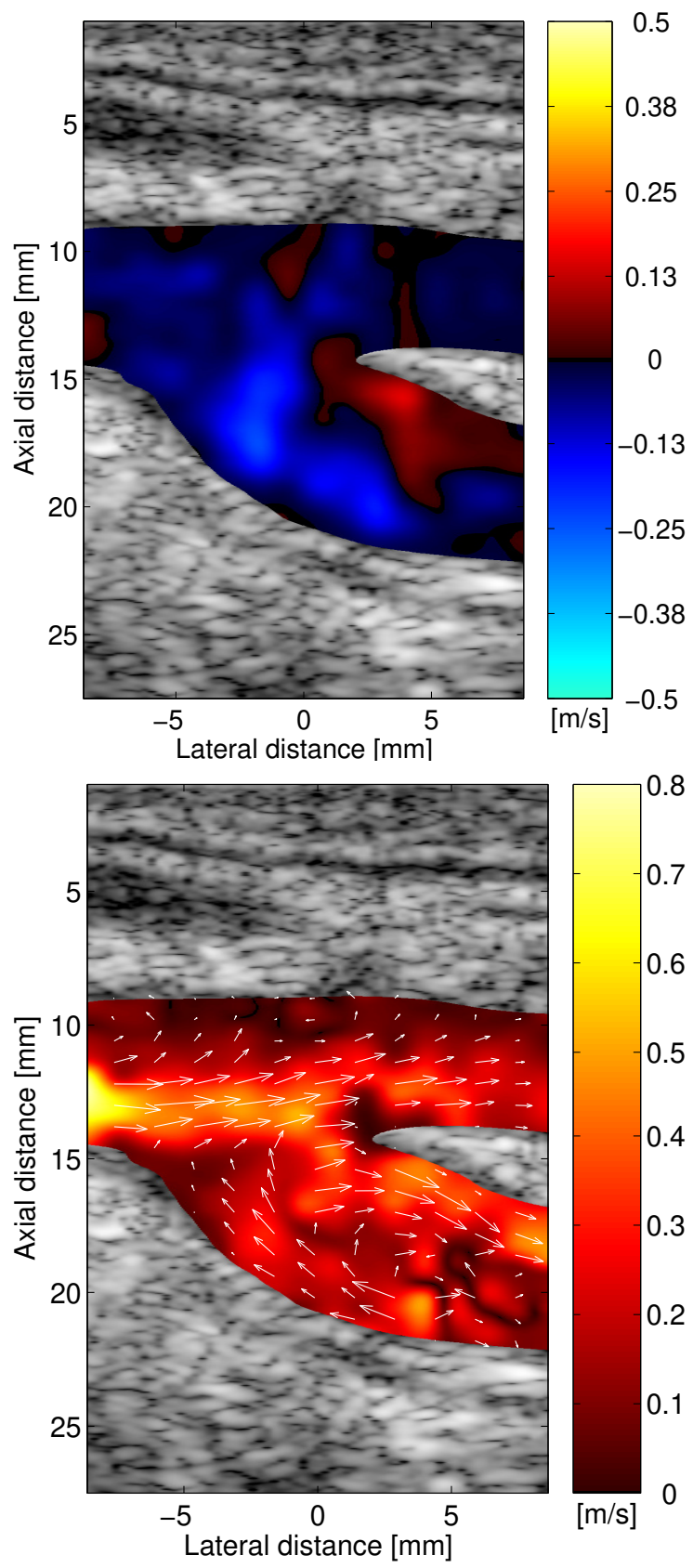

Fig. 1. In-vivo images of flow in the carotid bifurcation right before peak systole. The top images shows the CFM image for the axial velocity, and the bottom image shows the VFI using TO. A vortex is seen in the carotid bulb, and the velocity estimates are more consistent with what is found in the carotid artery (from [27]).

An example of flow in the aorta is shown in Fig. 2 for a short-axis view. The direction and velocity magnitude of the blood flow are displayed as colored pixels defined by the 2-D color bar with arrows superimposed for showing direction and magnitude. The short-axis view shows the rotation of the flow, which is nearly always found during the cardiac cycle, and the image demonstrates that the velocity can be estimated for all directions [28].

A range of studies have been conducted using the BK 


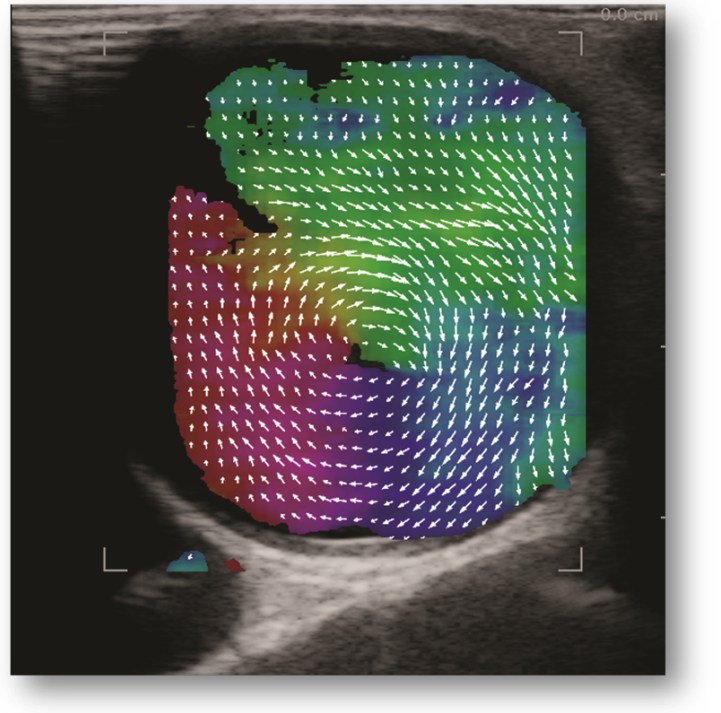

Fig. 2. Vector velocity imaging of blood flow in the ascending aorta in a short-axis view. The colors and arrows indicate velocity direction and magnitude (modified from [28]).

implementation. This includes investigating volume flow in arteriovenous fistulas [29], intraoperative cardiac examinations [30], flow in the aorta [28], flow in the ascending aorta for normal, stenotic and replaced aortic valves [31], and transthoracic VFI examination of newborns and infants with congenital heart defects [32]. Other groups have also investigated VFI and compared it to e.g. spectral velocity methods [33].

Vector flow is now also implemented on systems from Mindray and Toshiba, and a comprehensive review of all the developed methods can be found in [11], which also lists the comprehensive literature in the field for a range of different methods and clinical investigations.

\section{B. Quantitative Measurements in VFI}

Currently, quantification of velocities is obtained by using the axial velocity component from spectral velocity estimates, as the measurements are more precise than CFM results due to the continuous acquisition in one direction. The measurements have to be corrected for the beam-to-flow angle, and variations in this can lead to a serious bias. A $5^{\circ}$ error at a $60^{\circ}$ beamto-flow angle can lead to a $20 \%$ error in the velocity. VFI can automatically compensate such errors and can also handle that the beam-to-flow angle varies over the cardiac cycle. An example of quantitative VFI measurements is shown in Fig. 3, where both the mean value and the standard deviation (SD) can be estimated by measuring over several cardiac cycles [34].

Many other quantities can be derived from VFI data including flow complexity for revealing disturbed and turbulent flow [31, 35], volume flow [36], and pressure gradients [37]. In the last example, the pressure gradients are estimated by solving a simplified version of the Navier-Stokes equation with the VFI estimates as input. An example of this is shown in Fig. 4, where the top image shows the trajectory for the pressure gradient calculation, and the lower graph shows the mean

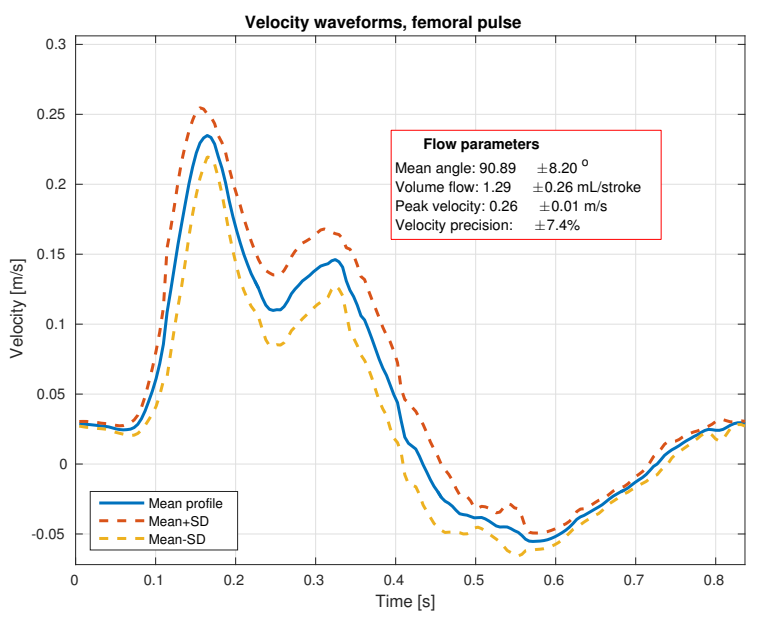

Fig. 3. Quantitative velocity measurements from a carotid phantom using a linear array probe with a directional TO velocity estimator (from [34]). Several cardiac cycles are automatically aligned and the mean value and SD are estimated from the 10 cycles for both the beam-to-flow angle and various velocity measures.

pressure gradient and its SD found from 11 cardiac cycles. The pressure gradient can be retrospectively found from the 10 seconds of data for any trajectory within the vector flow imaging region with a precision of $19 \%$. A large improvement compared to a pressure catheter, which had a relative SD of $786 \%$ [38].

\section{Synthetic Aperture Flow Imaging}

A major problem in conventional flow imaging is the sequential data acquisition, which limits the frame rate and the amount of data available for velocity estimation [12, 41]. This limits the penetration depth, the maximum detectable velocity, and the precision of the estimates. A break with this paradigm is to employ SA imaging as shown in Fig. 5, where the region of interest is broadly insonified by using spherical or plane waves. The scattered signal is then received on part or all of the elements, and a full Low Resolution Image (LRI) can be generated. Combining LRIs from a number of emissions then yields a High Resolution Image (HRI) dynamically focused in both transmit and receive. The focusing is performed by summing the waves in phase, and for spherical emissions the focusing times are calculated as:

$$
t_{i, j}=\frac{\left|\vec{r}_{i}-\vec{r}_{p}\right|}{c}+\frac{\left|\vec{r}_{j}-\vec{r}_{p}\right|}{c},
$$

where $\vec{r}_{i}$ is the origin of emission $i, \vec{r}_{p}$ is the location of the imaging point, and $\vec{r}_{j}$ is the position of the receiving element $j$. The high resolution image is then made by:

$$
y\left(\vec{r}_{p}\right)=\sum_{i=1}^{N_{i}} \sum_{j=1}^{N_{j}} a\left(\vec{r}_{i}, \vec{r}_{p}, \vec{r}_{j}\right) r\left(t_{i, j}\right),
$$

where $N_{i}$ is the number of transmissions and $N_{j}$ the number of receiving elements. Here $a()$ is the apodization function or relative weight between emissions and between receiving elements, which is often calculated from the F-number in transmit and receive. The same calculations are performed for 

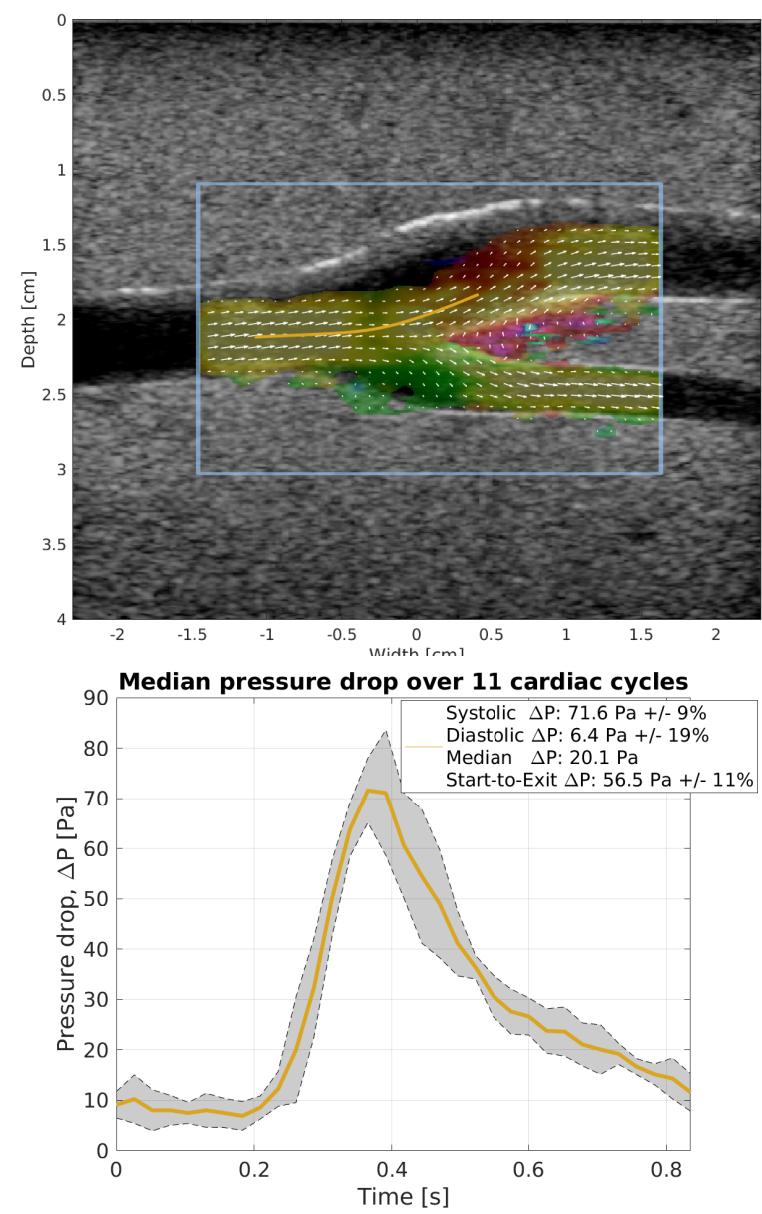

Fig. 4. Estimated pressure gradient from a carotid artery phantom. The top image shows the VFI and the trajectory for finding the pressure gradient (orange line). The lower graph shows the estimated pressure gradient from 11 cardiac cycles including the relative SD.

plane wave imaging with a replacement of the transmit delay (the first term in (1)) with the corresponding equation for a plane wave. This is often called ultrafast imaging [42], but the imaging scheme is really the same for both types of waves. The only difference is the calculation of the transmit delay in the beamforming, and we will, therefore, call both schemes for SA imaging in this paper. Creating SA images decouples frame rate from the number of lines in the image, and the frame rate is only determined by the number of emissions.

It might be counter-intuitive that such images acquired over multiple emissions can be used for velocity estimation, as the investigated object is moving between emissions and, thus, cannot be summed coherently. The initial idea for SA flow imaging is illustrated in Fig. 6, where a short sequence is used for SA imaging [43-45]. The emissions are shown on the top and the LRIs beneath. The bottom row shows the HRIs when the different LRIs are combined. A singe scatterer moving towards the probe is investigated. The LRIs are not summed in phase, and HRI $H^{(n-3)}$ is different from $H^{(n-2)}$, but equal to $H^{(n-1)}$ apart from the shift in position, where $n$ is the emission number. The basic idea is that the HRIs are highly correlated, if their emission sequences are the same. They may not be summed fully in phase, but the defocusing from motion is the same for all HRIs, as the emission sequence is the same. They can, therefore, be correlated to find the velocity.

This might seem like a small detail, but it has major implications for flow imaging. Firstly, imaging is continuous, and data are available everywhere in the imaging region for all time. It is, thus, possible to average the correlation functions over as long time as the flow can be considered stationary [46]. Also, flow can be followed in any direction, as data is available for the whole imaging region, and beamformation can be made in all directions. Any echo canceling filter can be used without detrimental initialization effects, making it much easier to separate out flow from tissue [47-50].

An example of the benefits from SA flow imaging can be seen in Fig. 7, which shows a velocity magnitude image acquired using an 8 emissions SA sequence [51]. The data have been beamformed along the flow direction and the velocity estimated by cross-correlating these directional lines for 16 HRIs, which yields the velocity magnitude. No post processing has been employed on the image, and only the raw estimates are shown. The relative standard deviation to the peak velocity is $0.3 \%$ for very precise quantitative data, ideal for the quantification described in Section II-B. Data can be beamformed in any direction, making it also possible to estimate transverse flow [51]. Methods for estimating the correct beam-to-flow angle have also been developed $[52,53]$.

The current state-of-the-art in SA flow imaging is shown in Fig. 8, where the flow in the carotid bifurcation is measured on a healthy volunteer [53]. Here, a five emissions sequence was used, and it can potentially yield more than 3000 frames per second. Images at three different time points in the cardiac cycle are shown at the top. The bottom graph shows the velocity magnitude estimated in the white circle in graph c). The evolution on the vortex in the carotid bulb can be studied in detail using such ultrafast imaging.

A major issue in these images is the very large amount of data and the significant number of calculations to conduct for creating real time imaging. The current trend is to employ fast GPUs to perform the beamforming and this can often approach real time imaging [54-57]. Another approach is to reduce the amount of data and thereby the calculation load. Dual stage beamforming has been developed to reduce the sampled data to one channel, and the processing demand is thereby also reduced proportionally. It was demonstrated in [58] that very fast SA VFI could be attained by this approach using TO and dual stage beamforming, and the processing could be performed in real time on a Tablet [59].

\section{A. Fast Flow}

One problem in SA imaging has been the reduction of the detectable peak velocity. For SA flow imaging the data has to be acquired over $N_{e}$ emissions, and the effective pulse repetition frequency $f_{p r f, e f f}$ is equal to $f_{p r f} / N_{e}$. The maximum detectable velocity $v_{\max }$ in velocity estimation is generally proportional to $\lambda f_{p r f, e f f}=v_{\max }$, which is reduced by a factor $N_{e}$ compared to traditional flow imaging. There is, 


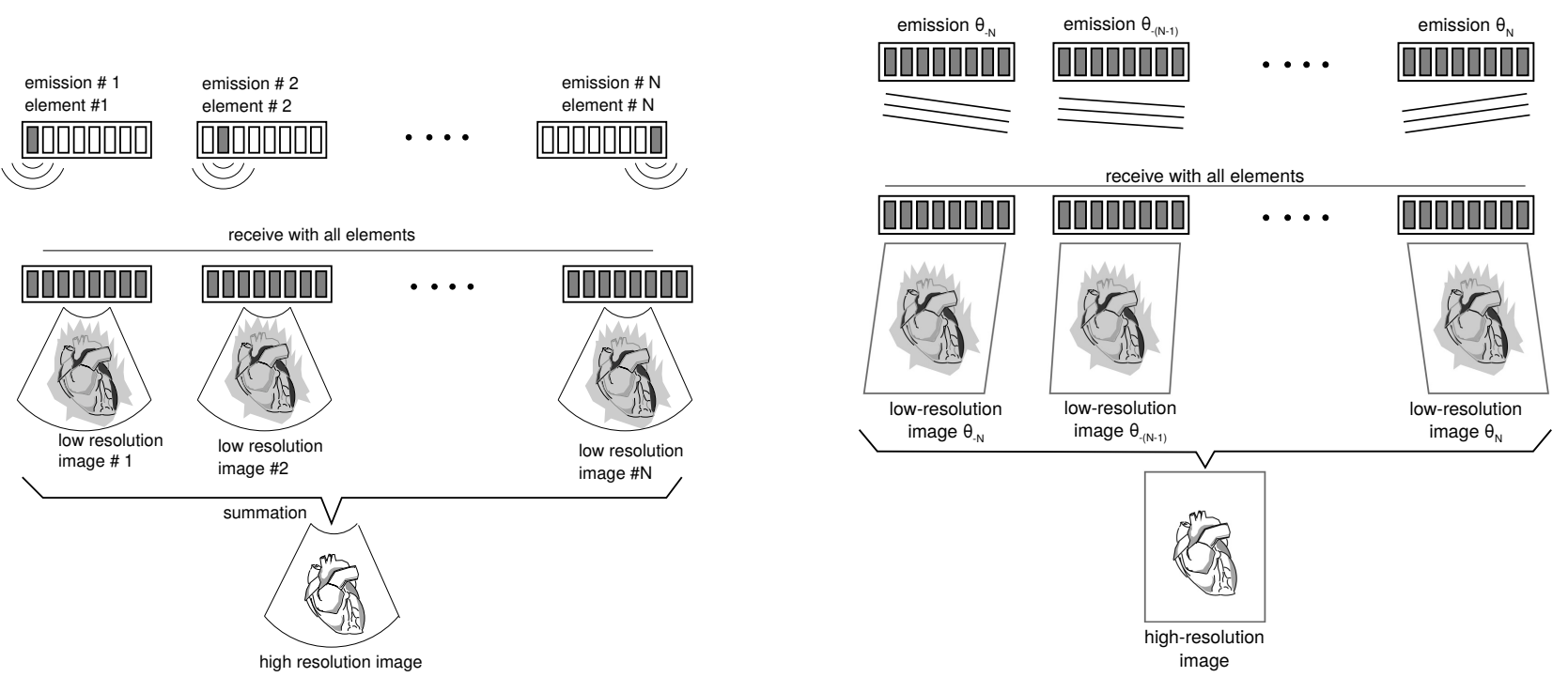

Fig. 5. Principle of SA imaging (left figure from [39]). The spherical emissions are shown on the top row with reception on all elements in the middle row. Plane wave imaging is shown in the right figure (from [40]).

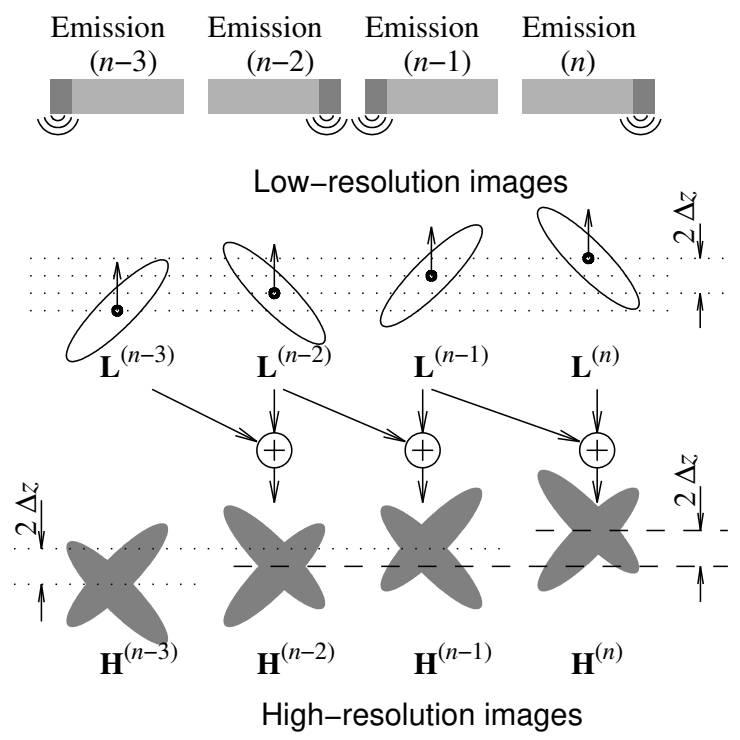

Fig. 6. Principle of SA flow imaging (from [43]).

thus, a compromise between sequence length and $v_{\max }$. Often a longer sequence is preferred to enhance contrast and this reduces $v_{\max }$. A possible solution is to use single emissions like in [61-64], but this reduces contrast and makes it difficult to estimate flow in small vessels.

The problem has recently been solved by introducing interleaved sequences, where an emission is repeated as shown in Fig. 9. The beamformed HRIs are then only temporally separated by $1 / f_{p r f}$ and not $1 / f_{p r f, e f f}$, and $v_{\max }$ is increased by a factor $N_{e}$. Combined with a cross-correlation estimator made it possible to estimate velocities above $5 \mathrm{~m} / \mathrm{s}$ for imaging down to $15 \mathrm{~cm}[60,65]$, and it is also possible to further increase the limit by using directional beamforming as in Fig. 7.

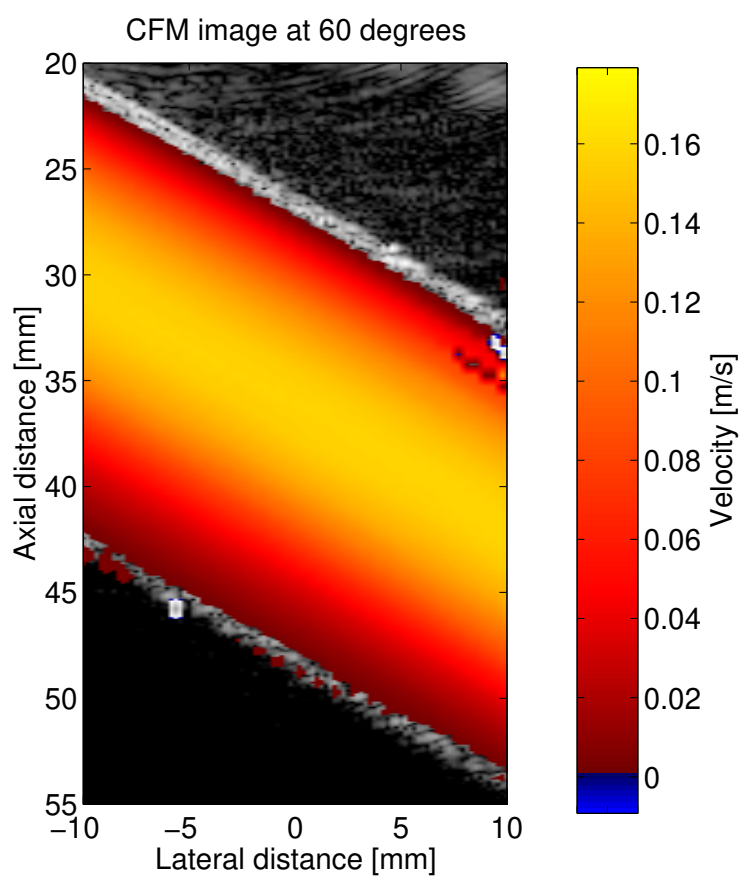

Fig. 7. Velocity magnitude velocity image acquired using SA flow imaging and directional beamforming (from [51]).

\section{B. Slow Flow}

A major advantage of continuous imaging is the possibility of using advanced echo canceling filters to separate flow from tissue. This is especially important for low velocities, and SA imaging has created major breakthroughs in studying slow flow in e.g. the rat brain as shown in Fig. 10 and the kidney $[66,67]$. In particular the employment of Singular Value Decomposition (SVD) echo canceling methods has benefited low velocity imaging and introduced a whole new range of possibilities $[47,50,68]$. 


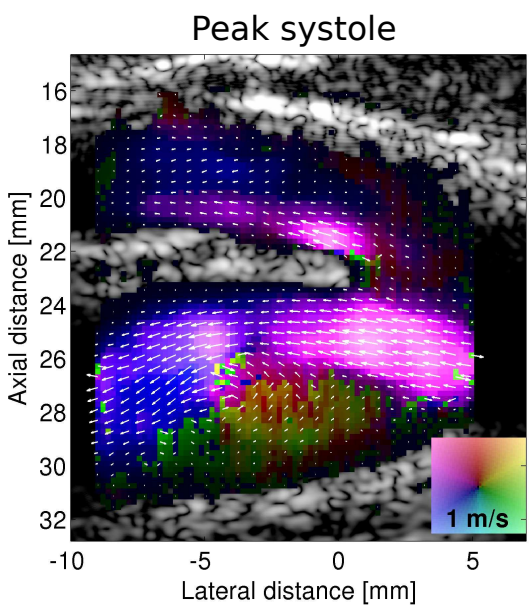

a)

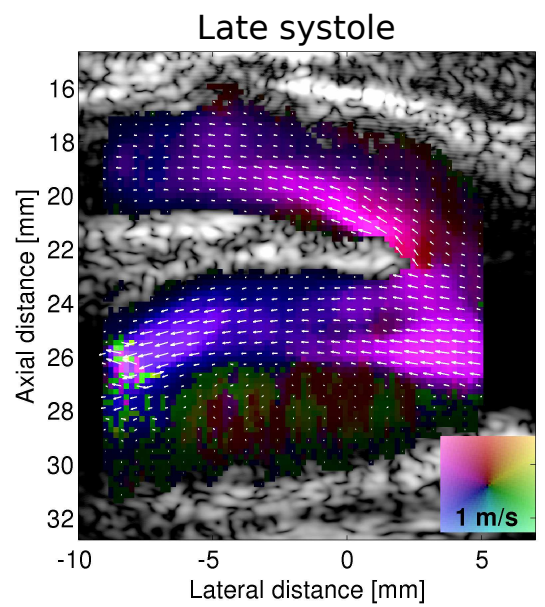

b)

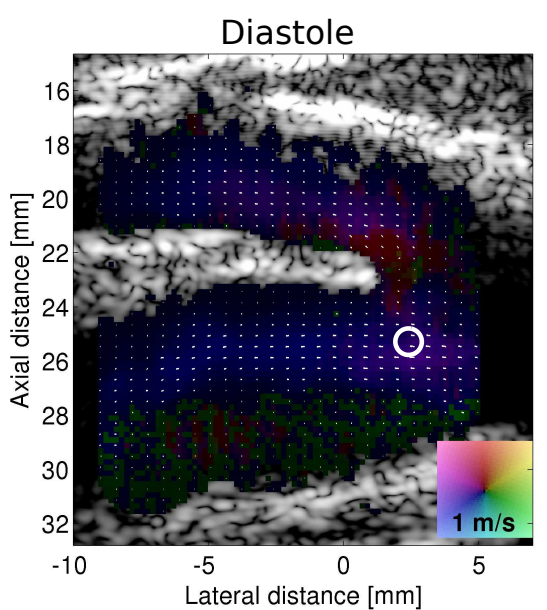

c)

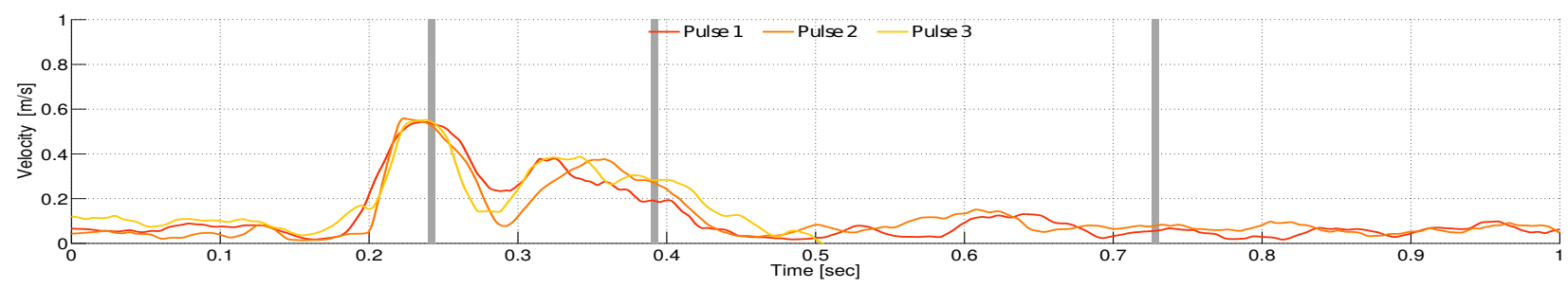

d)

Fig. 8. VFI acquired using a SA flow sequence and directional beamforming (from [53]). Images at three different time points in the cardiac cycle is shown on the top, and the measured velocity magnitude over time for three cardiac cycles are shown in the bottom figure.

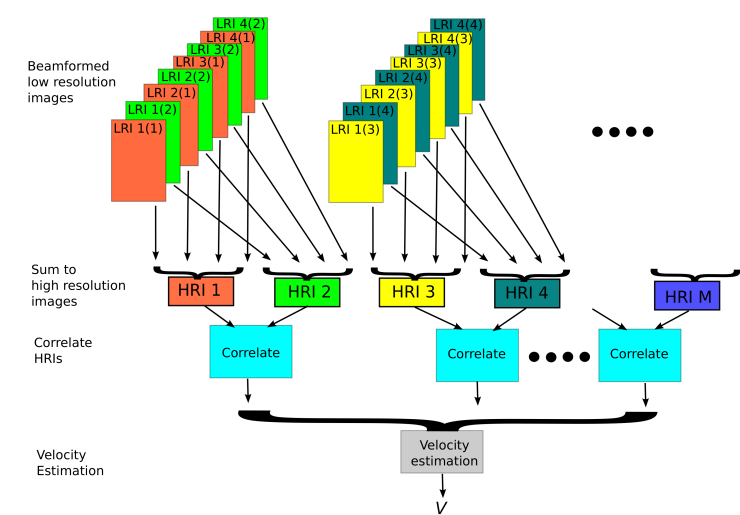

Fig. 9. Inter-leaved SA sequence where LRIs are repeated to minimize the distance between HRIs. The same colored LRIs are summed to yield one HRI. The effective $f_{\text {prf,eff }}$ is equal to the highest possible value $\left(f_{p r f}\right)$ due to the inter-leaving. Correlations in the blue boxes yield the same correlation function, which are then averaged to improve precision (from [60]).

\section{FROM 2-D TO 4-D}

The ultimate goal for VFI is to yield a full 3-D volumetric image at a high frame rate (4-D) with the full velocity vector determined for all three velocity components (3-D). This could be called 3-D VFI in 4-D. SA imaging can be used for this using matrix probes, where the emitted waves can be steered in all directions to insonify the whole volume continuously. The TO approach has been modified to estimate all three velocity components [71, 72]. A 1024 elements Vermon matrix probe

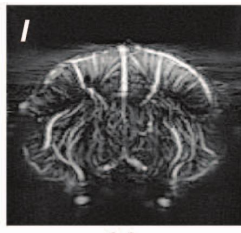

(a)

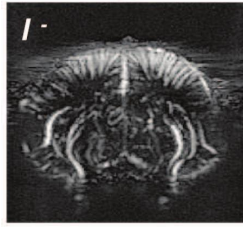

(c)

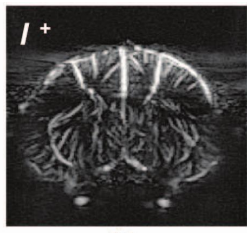

(b)

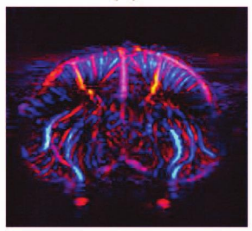

(d)

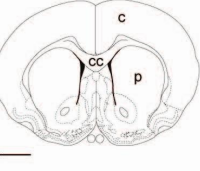

(e)
Fig. 10. Directional power Doppler. (a) Initial $\mu$ Doppler image. (b) Positive part of the Doppler power spectrum I+ quantifying the volume of blood flowing up. (c) Negative part of the Doppler power spectrum I quantifying the volume of blood flowing down. (d) Color-coded $\mu$ Doppler image: in each pixel, the positive part is colored on a red range of intensities and the negative part on a blue range of intensities. (e) Anatomy of the brain slice (bregma $+1.0 \mathrm{~mm}$ ). Main structures: cortex (denoted c), corpus callosum (cc) and caudate putamen (p). Scale bar: $2 \mathrm{~mm}$. (from [67]).

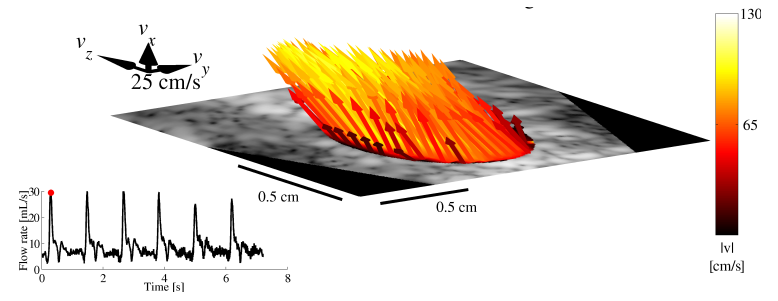

Fig. 11. Three-dimensional vector flow from the common carotid artery of a volunteer during peak systole using a 3-D TO estimator (modified from [69]). 


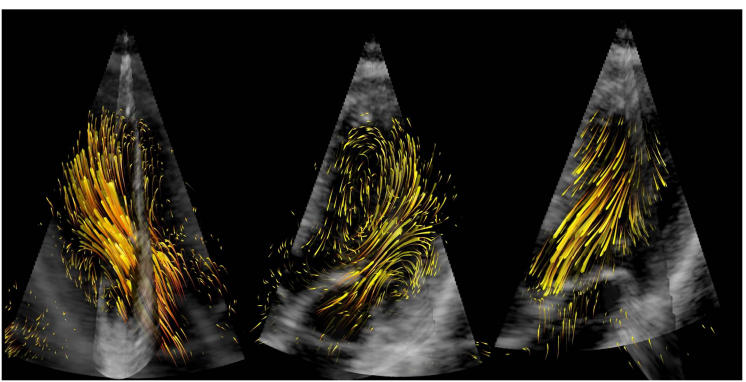

Fig. 12. Three-dimensional cardiac VFI rendering of the flow path lines at three time points in the cardiac cycle corresponding to diastole, diastasis, and systole. (from [70]).

[73] was used with the SARUS research scanner [74]. Invivo imaging of ten volunteers was conducted on the carotid artery in [69] as shown in Fig. 11, and the volume flow could be determined with a SD of 5.7\%. 3-D VFI has also been conducted in the heart using a modified GE Vivid E95 ultrasound scanner (GE Vingmed, Horten, Norway) using a GE 4V-D matrix array transducer for full volumetric coverage of the left ventricle at 50 volumes/second utilizing ECG-gating [70]. An example of these measurements is shown in Fig. 12.

One major problem is, however, the amount of elements needed. Both examples above use more than 1000 transducer elements, with probe foot-prints that are small, thus, impeding focusing. Good focusing in 2-D demands larger probes with 128 to 192 elements to maintain a low F-number for all imaging depths. Translating this to 3-D yields $192^{2}=36,864$ independent elements, which is impossible to connect through a cable to the scanner. A possible solution is to use a sparse array or electronic beamforming in the handle. This still restricts the number of elements to around 9,000 for roughly 100 elements on each side of the array. Low F-number focusing is therefore very difficult and expensive to attain in 3-D imaging, and compromises have to be made in both the imaging schemes and beamforming.

A novel solution to this problem is to employ Row-Column Arrays (RCAs), where rows and columns are independently addressed [75-78]. The number of interconnects is then transformed from $N^{2}$ to $2 N$, thus reducing it by a factor of $N / 2$. This makes very large arrays possible, and much lower Fnumbers can be maintained for larger depths. A further advantage of the large array size is the increased penetration depth. This again can be used for increasing the center frequency of the probe and thereby resolution. Arrays with only $64+64$ elements at $3 \mathrm{MHz}$ have attained a decent volumetric image quality and a penetration down to $30 \mathrm{~cm}$ for $\mathrm{SA}$ imaging sequences [79].

The RCAs can be combined with all the methods presented here, and, thereby, attain the previously mentioned advantages. Three-dimensional VFI was presented for a line and a plane in [81] and for a volume [80,81] using a $64+64 \mathrm{RC}$ array, and the TO approach adapted to 3-D VFI as shown in Fig. 13.

Recently, a SA RCA imaging sequence has also been developed using an interleaved sequence for fast imaging, high detectable velocities, and continuous data available in the full
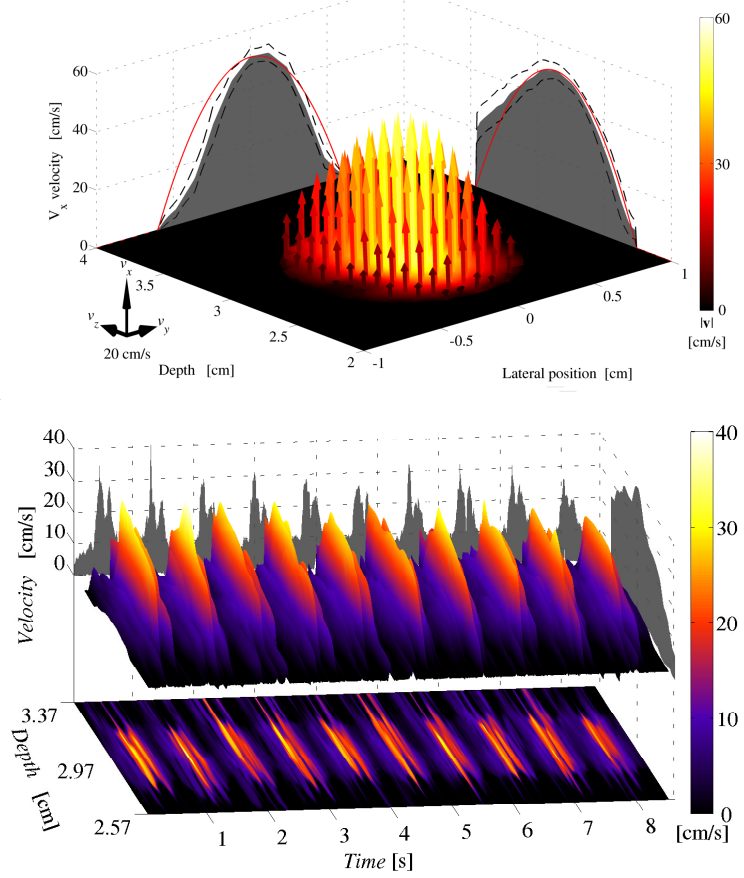

Fig. 13. Cross sectional mean 3-D vector flow averaged over 100 frames acquired using a $62+62$ element RCA. The magnitude and direction of the flow is depicted by the length and the color of the arrows on the top figure. The shaded gray areas represent the projection of the flow in the respective direction with their standard deviations (dotted line). The theoretical flow profiles are illustrated by the red lines. The bottom figure shows an M-mode of the out-of-plane $v_{x}$ velocity component measured for a pulsating carotid flow waveform (modified from [80])

volume [82]. Results from simulated flow with components in all directions are shown in Fig. 14, where the vessel is rotated $45^{\circ}=\beta$ compared to the probe, and the beam-to-flow angles $\alpha$ are $90^{\circ}, 75^{\circ}$, and $60^{\circ}$. All velocity components can be estimated with a bias less than $-6.2 \%$ and an SD below $4.5 \%$ for situations. An example of 3-D vector flow in 4-D is shown in Fig. 15, which was measured on pulsating flow in a bifurcation phantom using the $62+62$ RCA, SARUS and the SA sequence. It is possible to obtain new VFI estimates of all components and a B-mode image after 56 emissions, which yields 275 volumes/second for imaging down to $5 \mathrm{~cm}$. This demonstrates than quantitative 3-D VFI can be attained in a full volume at high volume rates (4-D) using only 62 receive channels.

The continuous data for SA RC imaging can also be employed for estimating low velocities using the methods described in Section III-B. Another example is to use super resolution imaging with $\mathrm{RC}$ arrays and ultrasound contrast agents. An example of this is shown in Fig. 16 for flow in a micro-phantom. The $3 \mathrm{MHz} 62+62$ array was used together with a $32+32$ emission SA pulse inversion sequence. The full volume was beamformed continuously, and the envelope signal was processed in a 3-D super resolution pipeline for bubble detection and presentation. A precision of roughly $20 \mu \mathrm{m}$ was attained in all three coordinates in the full volume [83]. 

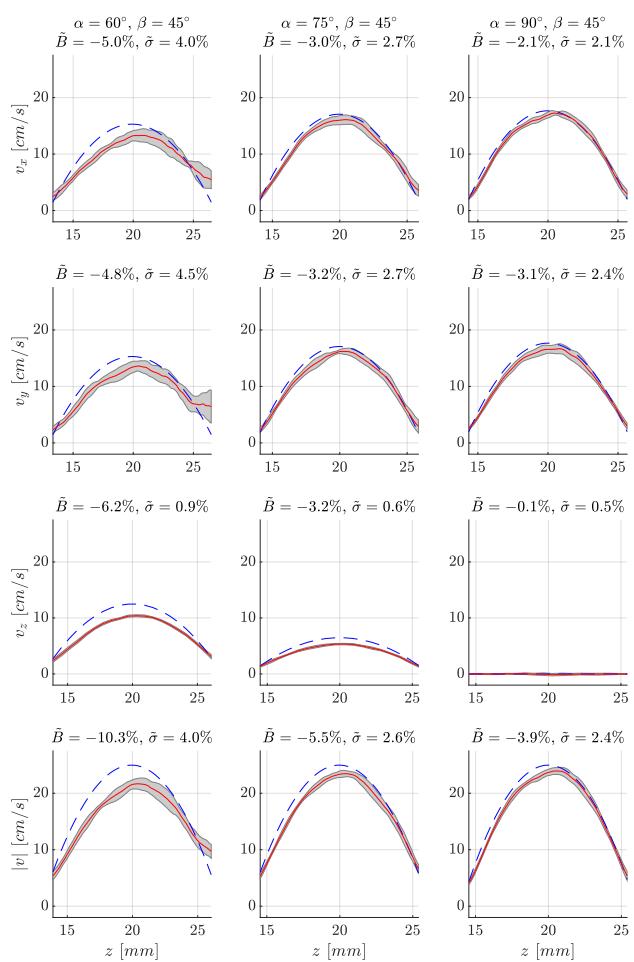

Fig. 14. Simulated velocity profiles for the SA RC flow sequence. The vessel $i$ rotated $45^{\circ}=\beta$ compared to the probe, and the beam-to-flow angles $\alpha$ are $90^{\circ}, 75^{\circ}$, and $60^{\circ}$. The true profiles are shown as dashed blue lines, the mean profiles are red, and the gray backgrounds show \pm 1 SD.

\section{RC 3-D VFI \\ Pulsating flow rig - CFU-005}

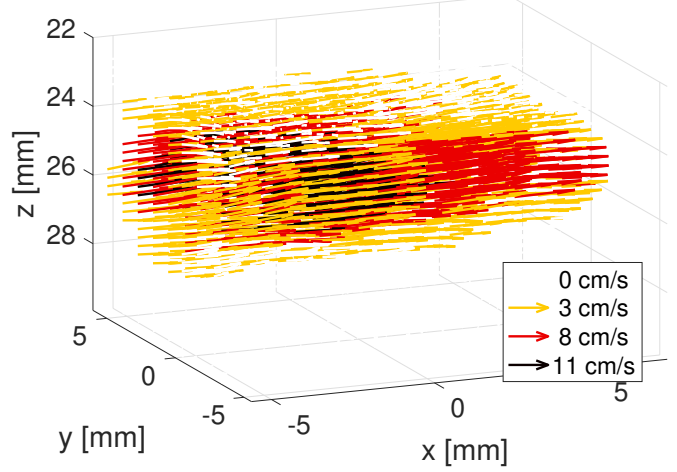

Fig. 15. Three-dimensional RC VFI from pulsating flow in a carotid artery phantom.

\section{Challenges AND OPPORTUNities}

Flow imaging has progressed in the last sixty years from simple 1-D measurements to the potential of revealing the full 3-D velocity vector in a full volume in real time at very high volumetric frame rates. The development has included new imaging schemes, new estimators and progress in making advanced arrays for both 2-D and 3-D imaging.

Many challenges still lie ahead. Larger 2-D probes should be developed to fully exploit the potential of RCA SA imaging. The field-of-view should also be expanded by employing e.g.

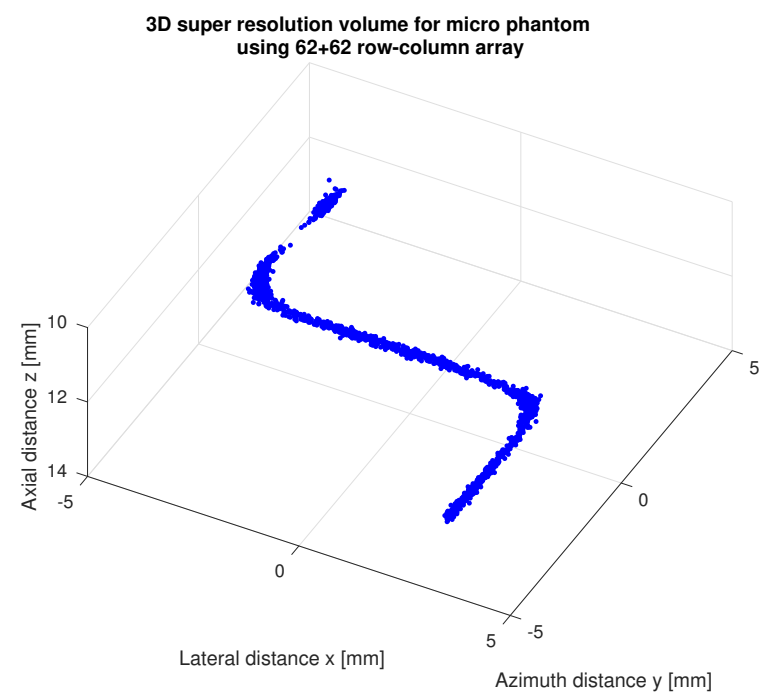

Fig. 16. Three-dimensional super resolution of of 3-D printed micro-phantom with a $200 \mu \mathrm{m}$ diameter channel. The blue dots each indicate a single detected bubble (from [83]).

lenses on the RC array as investigated in [79]. Much research is also needed for developing imaging schemes for such arrays using sparse sets of interleaved emissions to yield the fastest imaging with the fewest emissions for an optimal contrast and resolution. The years of development has also shown that new estimators can increase precision at the same time as the number of calculations is reduced by using TO estimators. This is quite a significant point, when real time flow estimation has to be conducted in a large volume at high frame rates. Echo canceling has been an object of intense research, and the new SVD based methods are very promising for separating flow from tissue, especially when employed on the new ultrafast SA sequences.

Implementation of the processing of the data from the probes is also a problem. The data rates from RC probes are comparable to the rates already processed in commercial consoles, but the output rate is higher since a full volume has to be made. Often, several volumes have to be made from the same data at a rate of $f_{p r f}$ for flow imaging, when 3-D VFI is made.

The large amount of 3-D data being made available at fast rates is a challenge to visualize and understand in the clinic, and new display methods have to be developed in collaboration with clinicians. It is especially important to keep in mind, what is usable in the clinic, and what can improve work flow and diagnostic reliability. The further development of quantitative measures can be an avenue for improving diagnostic information. Volume flow, peak velocities, and pressure gradients might be beneficial, and their precision can be directly deduced from the data for showing diagnostic reliability.

\section{ACKNOWLEDGMENT}

This work was financially supported by grant 82-2014-4 from the Danish National Advanced Technology Foundation, by grant 7050-00004B from Innovation Fund Denmark, and from BK Medical, Herlev, Denmark. 


\section{REFERENCES}

[1] S. Satomura, "Ultrasonic Doppler method for the inspection of cardiac functions," J. Acoust. Soc. Am., vol. 29, pp. 1181-1185, 1957.

[2] — "Study of the flow patterns in peripheral arteries by ultrasonics," J. Acoust. Soc. Jap., vol. 15, pp. 151-158, 1959.

[3] D. W. Baker, "Pulsed ultrasonic Doppler blood-flow sensing," IEEE Trans. Son. Ultrason., vol. SU-17, no. 3, pp. 170-185, 1970.

[4] P. N. T. Wells, "A range gated ultrasonic Doppler system," Med. Biol. Eng., vol. 7, pp. 641-652, 1969.

[5] K. Namekawa, C. Kasai, M. Tsukamoto, and A. Koyano, "Realtime bloodflow imaging system utilizing autocorrelation techniques," in $U l$ trasound '82, R. Lerski and P. Morley, Eds. New York: Pergamon Press, 1982, pp. 203-208.

[6] C. Kasai, K. Namekawa, A. Koyano, and R. Omoto, "Real-Time TwoDimensional Blood Flow Imaging using an Autocorrelation Technique," IEEE Trans. Son. Ultrason., vol. 32, no. 3, pp. 458-463, 1985.

[7] T. Loupas, J. T. Powers, and R. W. Gill, "An axial velocity estimator for ultrasound blood flow imaging, based on a full evaluation of the Doppler equation by means of a two-dimensional autocorrelation approach,' IEEE Trans. Ultrason., Ferroelec., Freq. Contr., vol. 42, pp. 672-688, 1995.

[8] T. Loupas, R. B. Peterson, and R. W. Gill, "Experimental evaluation of velocity and power estimation for blood flow imaging, by means of a two-dimensional autocorrelation approach," IEEE Trans. Ultrason., Ferroelec., Freq. Contr., vol. 42, pp. 689-699, 1995.

[9] P. M. Embree and W. D. O'Brien, "The accurate ultrasonic measurement of volume flow of blood by time-domain correlation," in Proc. IEEE Ultrason. Symp., 1985, pp. 963-966.

[10] O. Bonnefous and P. Pesqué, "Time domain formulation of pulseDoppler ultrasound and blood velocity estimation by cross correlation,' Ultrason. Imaging, vol. 8, pp. 73-85, 1986.

[11] J. A. Jensen, S. I. Nikolov, A. Yu, and D. Garcia, "Ultrasound vector flow imaging I: Sequential systems," IEEE Trans. Ultrason., Ferroelec., Freq. Contr., vol. 63, no. 11, pp. 1704-1721, 2016.

[12] - "Ultrasound vector flow imaging II: Parallel systems," IEEE Trans. Ultrason., Ferroelec., Freq. Contr., vol. 63, no. 11, pp. 1722-1732, 2016.

[13] M. D. Fox, "Multiple crossed-beam ultrasound Doppler velocimetry," IEEE Trans. Son. Ultrason., vol. SU-25, pp. 281-286, 1978.

[14] B. Dunmire, K. W. Beach, K.-H. Labs., M. Plett, and D. E. Strandness, "Cross-beam vector Doppler ultrasound for angle independent velocity measurements," Ultrasound Med. Biol., vol. 26, pp. 1213-1235, 2000.

[15] B. Dunmire and K. W. Beach, "A brief history of vector doppler," in Proc. SPIE Med. Imag., vol. 4325, Feb. 2001, pp. 200-214.

[16] G. E. Trahey, J. W. Allison, and O. T. von Ramm, "Angle independent ultrasonic detection of blood flow," IEEE Trans. Biomed. Eng., vol. BME-34, no. 12, pp. 965-967, 1987.

[17] J. A. Jensen and P. Munk, "A new method for estimation of velocity vectors," IEEE Trans. Ultrason., Ferroelec., Freq. Contr., vol. 45, no. 3 , pp. 837-851, 1998.

[18] M. E. Anderson, "Multi-dimensional velocity estimation with ultrasound using spatial quadrature," IEEE Trans. Ultrason., Ferroelec., Freq. Contr., vol. 45, pp. 852-861, 1998.

[19] J. A. Jensen, Estimation of Blood Velocities Using Ultrasound: A Signal Processing Approach. New York: Cambridge University Press, 1996.

[20] J. W. Goodman, Introduction to Fourier optics, 2nd ed. New York: McGraw Hill Inc., 1996.

[21] J. Udesen and J. A. Jensen, "Investigation of transverse oscillation method," IEEE Trans. Ultrason., Ferroelec., Freq. Contr., vol. 53, pp. 959-971, 2006.

[22] J. A. Jensen, "A new estimator for vector velocity estimation," IEEE Trans. Ultrason., Ferroelec., Freq. Contr., vol. 48, no. 4, pp. 886-894, 2001.

[23] P. M. Hansen, M. M. Pedersen, K. L. Hansen, M. B. Nielsen, and J. A. Jensen, "Demonstration of a vector velocity technique," Ultraschall in Med., vol. 32, pp. 213-215, 2011.

[24] J. A. Jensen, A. H. Brandt, and M. B. Nielsen, "Convex array vector velocity imaging using transverse oscillation and its optimization," IEEE Trans. Ultrason., Ferroelec., Freq. Contr., vol. 62, no. 12, pp. 20432053, 2015.

[25] M. J. Pihl, J. Marcher, and J. A. Jensen, "Phased-array vector velocity estimation using transverse oscillations," IEEE Trans. Ultrason., Ferroelec., Freq. Contr., vol. 59, no. 12, pp. 2662-2675, 2012.

[26] J. A. Jensen, "Transverse spectral velocity estimation," IEEE Trans. Ultrason., Ferroelec., Freq. Contr., vol. 61, no. 11, pp. 1815-1823, 2014
[27] J. Udesen, M. B. Nielsen, K. R. Nielsen, and J. A. Jensen, "Examples of in-vivo blood vector velocity estimation," Ultrasound Med. Biol., vol. 33, pp. 541-548, 2007.

[28] K. L. Hansen, H. Møller-Sørensen, J. Kjaergaard, J. T. Lund, M. M. Pedersen, T. Lange, J. A. Jensen, and M. B. Nielsen, "Analysis of systolic backflow and secondary helical blood flow in the ascending aorta using vector flow imaging," Ultrasound Med. Biol., vol. 42, no. 4, pp. 899-908, 2016.

[29] P. M. Hansen, J. B. Olesen, M. J. Pihl, T. Lange, S. Heerwagen, M. M. Pedersen, M. Rix, L. Lönn, J. A. Jensen, and M. B. Nielsen, "Volume flow in arteriovenous fistulas using vector velocity ultrasound," Ultrasound Med. Biol., vol. 40, no. 11, pp. 2707-2714, 2014.

[30] K. L. Hansen, M. M. Pedersen, H. Møller-Sørensen, J. Kjaergaard, J. C. Nilsson, J. T. Lund, J. A. Jensen, and M. B. Nielsen, "Intraoperative cardiac ultrasound examination using vector flow imaging," Ultrason. Imaging, vol. 35, no. 4, pp. 318-332, Oct 2013.

[31] K. L. Hansen, H. Møller-Sørensen, J. Kjaergaard, M. B. Jensen, J. T. Lund, M. M. Pedersen, T. Lange, J. A. Jensen, and M. B. Nielsen, "Intraoperative vector flow imaging using ultrasound of the ascending aorta among 40 patients with normal, stenotic and replaced aortic valves," Ultrasound Med. Biol., vol. 42, no. 10, pp. 2414-2422, 2016.

[32] K. L. Hansen, K. Juul, H. Møller-Sørensen, J. C. Nilsson, J. A. Jensen, and M. B. Nielsen, "Pediatric transthoracic cardiac vector flow imaging - A preliminary pictorial study," Ultrasound International Open, vol. 5, no. 1, pp. E20-E26, 2019.

[33] P. Tortoli, M. Lenge, D. Righi, G. Ciuti, H. Liebgott, and S. Ricci, "Comparison of carotid artery blood velocity measurements by vector and standard Doppler approaches," Ultrasound Med. Biol., vol. 41, no. 5, pp. 1354-1362, 2015.

[34] J. A. Jensen, "Directional transverse oscillation vector flow estimation," IEEE Trans. Ultrason., Ferroelec., Freq. Contr., vol. 64, no. 8, pp. 1194 1204, 2017.

[35] K. L. Hansen, H. Møller-Sørensen, J. Kjaergaard, M. B. Jensen, J. A. Jensen, and M. B. Nielsen, "Aortic valve stenosis increases helical flow and flow complexity: A study of intra-operative cardiac vector flow imaging," Ultrasound Med. Biol., vol. 43, no. 8, pp. 1607-1617, 2017.

[36] J. Jensen, J. B. Olesen, P. M. Hansen, M. B. Nielsen, and J. A. Jensen, "Accuracy and sources of error for an angle independent volume flow estimator," Proc. IEEE Ultrason. Symp., pp. 1714-1717, 2014.

[37] J. B. Olesen, C. A. Villagómez Hoyos, N. D. Møller, C. Ewertsen, K. L. Hansen, M. B. Nielsen, B. Bech, L. Lönn, M. S. Traberg, and J. A. Jensen, "Non-invasive estimation of pressure changes using 2-D vector velocity ultrasound: An experimental study with in-vivo examples," IEEE Trans. Ultrason., Ferroelec., Freq. Contr., vol. 65, no. 5, pp. 709719, 2018.

[38] T.-Q. Nguyen, M. S. Traberg, J. B. Olesen, P. H. Møller-Sørensen, R. Moshavegh, L. Lönn, J. A. Jensen, M. B. Nielsen, and K. L. Hansen, "Pressure difference estimation in carotid bulbs using vector flow imaging - a phantom study," in Proc. IEEE Ultrason. Symp., 2019, pp. $1-4$.

[39] S. I. Nikolov, "Synthetic aperture tissue and flow ultrasound imaging," Ph.D. dissertation, Ørsted•DTU, Technical University of Denmark, 2800, Lyngby, Denmark, 2001.

[40] J. Jensen, "Fast plane wave imaging," Ph.D. dissertation, DTU Elektro, Technical University of Denmark, 2017.

[41] J. A. Jensen, S. Nikolov, K. L. Gammelmark, and M. H. Pedersen, "Synthetic aperture ultrasound imaging," Ultrasonics, vol. 44, pp. e5e15, 2006.

[42] M. Tanter and M. Fink, "Ultrafast imaging in biomedical ultrasound," IEEE Trans. Ultrason., Ferroelec., Freq. Contr., vol. 61, no. 1, pp. 102119, January 2014

[43] S. I. Nikolov and J. A. Jensen, "In-vivo synthetic aperture flow imaging in medical ultrasound," IEEE Trans. Ultrason., Ferroelec., Freq. Contr., vol. 50, no. 7, pp. 848-856, 2003.

[44] — "Velocity estimation using synthetic aperture imaging," in Proc IEEE Ultrason. Symp., 2001, pp. 1409-1412.

[45] J. A. Jensen, S. I. Nikolov, T. Misaridis, and K. L. Gammelmark, "Equipment and methods for synthetic aperture anatomic and flow imaging," in Proc. IEEE Ultrason. Symp., 2002, pp. 1555-1564.

[46] N. Oddershede and J. A. Jensen, "Effects influencing focusing in synthetic aperture vector flow imaging," IEEE Trans. Ultrason., Ferroelec., Freq. Contr., vol. 54, no. 9, pp. 1811-1825, 2007.

[47] L. A. F. Ledoux, P. J. Brands, and A. P. G. Hoeks, "Reduction of the clutter component in Doppler ultrasound signals based on singular value 
decomposition: A simulation study," Ultrason. Imaging, pp. 1-18, 1997.

[48] L. Løvstakken, S. Bjærum, and H. Torp, "Optimal velocity estimation in ultrasound color flow imaging in presence of clutter," IEEE Trans. Ultrason., Ferroelec., Freq. Contr., vol. 54, no. 3, pp. 539-549, March 2007.

[49] A. C. H. Yu and L. Løvstakken, "Eigen-based clutter filter design for ultrasound color flow imaging: a review," IEEE Trans. Ultrason., Ferroelec., Freq. Contr., vol. 57, no. 5, pp. 1096-1111, 2010.

[50] C. Demene, T. Deffieux, M. Pernot, B.-F. Osmanski, V. Biran, J.-L. Gennisson, L.-A. Sieu, A. Bergel, S. Franqui, J.-M. Correas, I. Cohen, O. Baud, and M. Tanter, "Spatiotemporal clutter filtering of ultrafast ultrasound data highly increases Doppler and fUltrasound sensitivity," IEEE Trans. Med. Imag., vol. 34, no. 11, pp. 2271-2285, 2015.

[51] J. A. Jensen and S. I. Nikolov, "Directional synthetic aperture flow imaging," IEEE Trans. Ultrason., Ferroelec., Freq. Contr., vol. 51, pp. 1107-1118, 2004

[52] J. A. Jensen and N. Oddershede, "Estimation of velocity vectors in synthetic aperture ultrasound imaging," IEEE Trans. Med. Imag., vol. 25 pp. 1637-1644, 2006.

[53] C. A. Villagomez-Hoyos, M. B. Stuart, K. L. Hansen, M. B. Nielsen, and J. A. Jensen, "Accurate angle estimator for high frame rate 2-D vector flow imaging," IEEE Trans. Ultrason., Ferroelec., Freq. Contr., vol. 63, no. 6, pp. 842-853, 2016.

[54] B. Y. S. Yiu, I. K. H. Tsang, and A. C. H. Yu, "GPU-based beamformer: Fast realization of plane wave compounding and synthetic aperture imaging," IEEE Trans. Ultrason., Ferroelec., Freq. Contr., vol. 58, no. 7, pp. 1698-1705, 2011.

[55] J. M. Hansen, D. Schaa, and J. A. Jensen, "Synthetic aperture beamformation using the GPU," in Proc. IEEE Ultrason. Symp., 2011, pp. 373-376.

[56] M. Lewandowski, M. Walczak, B. Witek, P. Kulesza, and K. Sielewicz, "Modular \& scalable ultrasound platform with GPU processing," Proc. IEEE Ultrason. Symp., pp. 1-4, 2012.

[57] M. B. Stuart, M. Schou, and J. A. Jensen, "Row-column beamforming with dynamic apodizations on a GPU," in Proc. SPIE Med. Imag., 2019, pp. 1-7, paper number 10955-20.

[58] T. di Ianni, K. L. Hansen, C. A. V. Hoyos, R. Moshavegh, M. B. Nielsen, and J. A. Jensen, "Portable vector flow imaging compared with spectral doppler ultrasonography," IEEE Trans. Ultrason., Ferroelec., Freq. Contr., vol. 66, no. 3, pp. 453-462, 2018.

[59] T. Di Ianni, T. Kjeldsen, C. Villagomez-Hoyos, J. Mosegaard, and J. A. Jensen, "Real-time implementation of synthetic aperture vector flow imaging in a consumer-level tablet," in Proc. IEEE Ultrason. Symp., 2017, pp. 1-4.

[60] J. A. Jensen, "Estimation of high velocities in synthetic aperture imaging: I: Theory," IEEE Trans. Ultrason., Ferroelec., Freq. Contr., vol. 66, no. 6 , pp. 1024-1031, 2019.

[61] M. Tanter, J. Bercoff, L. Sandrin, and M. Fink, "Ultrafast compound imaging for 2-D motion vector estimation: application to transient elastography," IEEE Trans. Ultrason., Ferroelec., Freq. Contr., vol. 49, pp. 1363-1374, 2002.

[62] J. Udesen, F. Gran, K. L. Hansen, J. A. Jensen, C. Thomsen, and M. B. Nielsen, "High frame-rate blood vector velocity imaging using plane waves: Simulations and preliminary experiments," IEEE Trans. Ultrason., Ferroelec., Freq. Contr., vol. 55, no. 8, pp. 1729-1743, 2008.

[63] K. L. Hansen, J. Udesen, F. Gran, J. A. Jensen, and M. B. Nielsen, "Invivo examples of flow patterns with the fast vector velocity ultrasound method," Ultraschall in Med., vol. 30, pp. 471-476, 2009.

[64] S. Fadnes, S. A. Nyrnes, H. Torp, and L. Lovstakken, "Shunt flow evaluation in congenital heart disease based on two-dimensional speckle tracking," Ultrasound Med. Biol., vol. 40, no. 10, pp. 2379-2391, 2014.

[65] J. A. Jensen, "Estimation of high velocities in synthetic aperture imaging: II: Experimental investigation," IEEE Trans. Ultrason., Ferroelec., Freq. Contr, vol. 66, no. 6, pp. 1032-1038, 2019.

[66] E. Mace, G. Montaldo, I. Cohen, M. Baulac, M. Fink, and M. Tanter, "Functional ultrasound imaging of the brain," Nature methods, vol. 8, no. 8, pp. 662-664, 2011.

[67] E. Mace, G. Montaldo, B. Osmanski, I. Cohen, M. Fink, and M. Tanter, "Functional ultrasound imaging of the brain: Theory and basic principles," IEEE Trans. Ultrason., Ferroelec., Freq. Contr., vol. 60, no. 3, pp. 492-506, 2013.

[68] J. Baranger, B. Arnal, F. Perren, O. Baud, M. Tanter, and C. Demene, "Adaptive spatiotemporal SVD clutter filtering for ultrafast Doppler imaging using similarity of spatial singular vectors," IEEE Trans. Med.
Imag., vol. 37, no. 7, pp. 1574-1586, July 2018.

[69] S. Holbek, K. H. Lindskov, H. Bouzari, C. Ewertsen, M. B. Stuart, C. Thomsen, M. B. Nielsen, and J. A. Jensen, "Common carotid artery flow measured by 3-D ultrasonic VFI and validated with MRI," Ultrasound Med. Biol., vol. 43, no. 10, pp. 2213-2220, 2017.

[70] M. S. Wigen, S. Fadnes, A. Rodriguez-Molares, T. Bjåstad, M. Eriksen, K. H. Stensæth, A. Støylen, and L. Løvstakken, "4-D intracardiac ultrasound vector flow imaging-reasibility and comparison to phasecontrast MRI," IEEE Trans. Med. Imag., vol. 37, no. 12, pp. 2619-2629, December 2018.

[71] M. J. Pihl and J. A. Jensen, "A transverse oscillation approach for estimation of three-dimensional velocity vectors. Part I: Concept and simulation study," IEEE Trans. Ultrason., Ferroelec., Freq. Contr., vol. 61, pp. 1599-1607, 2014.

[72] M. J. Pihl, M. B. Stuart, B. G. Tomov, M. F. Rasmussen, and J. A. Jensen, "A transverse oscillation approach for estimation of threedimensional velocity vectors. Part II: Experimental validation," IEEE Trans. Ultrason., Ferroelec., Freq. Contr., vol. 51, no. 10, pp. 16081618, 2014.

[73] L. Ratsimandresy, P. Mauchamp, D. Dinet, N. Felix, and R. Dufait, "A $3 \mathrm{MHz}$ two dimensional array based on piezocomposite for medical imaging," in Proc. IEEE Ultrason. Symp., 2002, pp. 1265-1268.

[74] J. A. Jensen, H. Holten-Lund, R. T. Nilsson, M. Hansen, U. D. Larsen, R. P. Domsten, B. G. Tomov, M. B. Stuart, S. I. Nikolov, M. J. Pihl, Y. Du, J. H. Rasmussen, and M. F. Rasmussen, "SARUS: A synthetic aperture real-time ultrasound system," IEEE Trans. Ultrason., Ferroelec., Freq. Contr., vol. 60, no. 9, pp. 1838-1852, 2013.

[75] C. E. Morton and G. R. Lockwood, "Theoretical assessment of a crossed electrode 2-D array for 3-D imaging," in Proc. IEEE Ultrason. Symp., 2003, pp. 968-971.

[76] N. M. Daher and J. T. Yen, "2-D array for 3-D ultrasound imaging using synthetic aperture techniques," IEEE Trans. Ultrason., Ferroelec., Freq. Contr., vol. 53, no. 5, pp. 912-924, 2006.

[77] M. F. Rasmussen, T. L. Christiansen, E. V. Thomsen, and J. A. Jensen, "3-D imaging using row-column-addressed arrays with integrated apodization - Part I: Apodization design and line element beamforming," IEEE Trans. Ultrason., Ferroelec., Freq. Contr., vol. 62, no. 5, pp. 947-958, 2015.

[78] T. L. Christiansen, M. F. Rasmussen, J. P. Bagge, L. N. Moesner, J. A. Jensen, and E. V. Thomsen, "3-D imaging using row-column-addressed arrays with integrated apodization - part II: Transducer fabrication and experimental results," IEEE Trans. Ultrason., Ferroelec., Freq. Contr., vol. 62 , no. 5 , pp. 959-971, 2015.

[79] H. Bouzari, M. Engholm, S. I. Nikolov, M. B. Stuart, E. V. Thomsen, and J. A. Jensen, "Imaging performance for two row-column arrays," IEEE Trans. Ultrason., Ferroelec., Freq. Contr., vol. 66, no. 7, pp. 1209-1221, 2019.

[80] S. Holbek, T. L. Christiansen, M. B. Stuart, C. Beers, E. V. Thomsen, and J. A. Jensen, "3-D vector flow estimation with row-column addressed arrays," IEEE Trans. Ultrason., Ferroelec., Freq. Contr., vol. 63, no. 11, pp. 1799-1814, 2016.

[81] S. Holbek, T. L. Christiansen, M. F. Rasmussen, M. B. Stuart, E. V. Thomsen, and J. A. Jensen, "3-D vector velocity estimation with rowcolumn addressed arrays," in Proc. IEEE Ultrason. Symp., 2015, pp. $1-4$.

[82] M. Schou, L. T. Jørgensen, M. B. Stuart, M. S. Traberg, B. G. Tomov, and J. A. Jensen, "Full volumetric 3-D vector flow imaging using a 62+62 row-column array," in Proc. IEEE Ultrason. Symp., 2019, pp. $1-4$.

[83] J. A. Jensen, M. L. Ommen, S. H. Øygard, M. Schou, T. Sams, M. B. Stuart, C. Beers, E. V. Thomsen, N. B. Larsen, , and B. G. Tomov, "Three-dimensional super resolution imaging using a row-column array," IEEE Trans. Ultrason., Ferroelec., Freq. Contr., p. Submitted, 2019. 